\title{
Ecosystem greenspots: identifying potential drought, fire, and climate-change micro-refuges
}

\author{
Brendan Mackey, ${ }^{1,3}$ Sandra Berry,${ }^{1}$ Sonia Hugh,${ }^{1}$ Simon Ferrier,${ }^{2}$ Thomas D. Harwood,${ }^{2}$ \\ AND Kristen J. Williams ${ }^{2}$ \\ ${ }^{1}$ The Fenner School of Environment and Society, The Australian National University, Canberra ACT 0200 Australia \\ ${ }^{2}$ CSIRO Ecosystem Sciences, Climate Adaptation Flagship
}

\begin{abstract}
In response to climate change and other threatening processes there is renewed interest in the role of refugia and refuges. In bioregions that experience drought and fire, micro-refuges can play a vital role in ensuring the persistence of species. We develop and apply an approach to identifying potential micro-refuges based on a time series of remotely sensed vegetation greenness (fraction of photosynthetically active radiation intercepted by the sunlit canopy; fPAR). The primary data for this analysis were NASA MODIS 16-day L3 Global 250 $\mathrm{m}$ (MOD13Q1) satellite imagery. This method draws upon relevant ecological theory (sourcesink habitats, habitat templet) to calculate a micro-refuge index, which is analyzed for each of the major vegetation ecosystems in the case-study region (the Great Eastern Ranges of New South Wales, Australia). Potential ecosystem greenspots were identified, at a range of thresholds, based on an index derived from: the mean and coefficient of variance (COV) of fPAR over the 10-year time series; the minimum mean annual fPAR; and the COV of the 12 values of mean monthly fPAR. These greenspots were mapped and compared with (1) an index of vascular plant species composition, (2) environmental variables, and (3) protected areas. Potential micro-refuges were found within all vegetation ecosystem types. The total area of ecosystem greenspots within the upper $25 \%$ threshold was 48406 ha; around $0.2 \%$ of the total area of native vegetation $\left(23.9 \times 10^{6} \mathrm{ha}\right)$ in the study region. The total area affected by fire was $3.4 \times 10^{6}$ ha. The results of the environmental diagnostic analysis suggest deterministic controls on the geographical distribution of potential micro-refuges that may continue to function under climate change. The approach is relevant to other regions of the world where the role of micro-refuges in the persistence of species is recognized, including across the world's arid zones and, in particular, for the Australian, southern African, and South American continents. Micro-refuge networks may play an important role in maintaining betadiversity at the bio-region scale and contribute to the stability, resilience, and adaptive capacity of ecosystems in the face of ever-growing pressures from human-forced climate change, land use, and other threatening processes.
\end{abstract}

Key words: climate change; drought; ecosystem adaptive capacity; ecosystem greenspots; fire; Great Eastern Range, New South Wales, Australia; habitat productivity; MODIS; micro-refuges; refugia.

\section{INTRODUCTION}

In this paper we consider the problem of identifying habitat refuges and potential refuges in the context of drought, fire, and climate change.

The concepts of refuges and refugia are related and often treated as equivalent. "Refugia" have been defined as locations, sometimes functioning as networks, that provide suitable habitat for species when prevailing conditions change such that (1) the necessary habitat resources needed for food, shelter and nesting become unavailable over the majority of the species range, (2) the environmental regimes (including climatic regimes)

Manuscript received 18 August 2011; revised 31 January 2012; accepted 16 February 2012; final version received 13 March 2012. Corresponding Editor: T. G. O’Brien.

${ }^{3}$ Present address: Griffith Climate Change Response Program, Gold Coast Campus, Griffith University, Queensland 4222 Australia. E-mail: b.mackey@griffith.edu.au over the species range fall outside the conditions that match the species physiological niche, or (3) a combination of the two (Mackey et al. 2002) (note that these locations may also support habitat specialists not found in the wider landscape). However, the term "refugia" is more commonly used in the context of "glacial" (Bennett and Provan 2008) or "interglacial" refugia (Stewart et al. 2010) where the relevant timescales of the threatening processes (climate change) are millennial or longer. Keppel et al. (2011) made the distinction between refuges and refugia on the basis of the latter reflecting longer timescales associated with species-range dynamics and global climate change. The concepts of habitat refuges and refugia have been widely applied. Habitat refuges have been studied with respect to, among other things, the impact on species of drought (Morton et al. 1995) and fire (Mackey et al. 2002). Investigations on past climate-change refugia have focused on the impact 


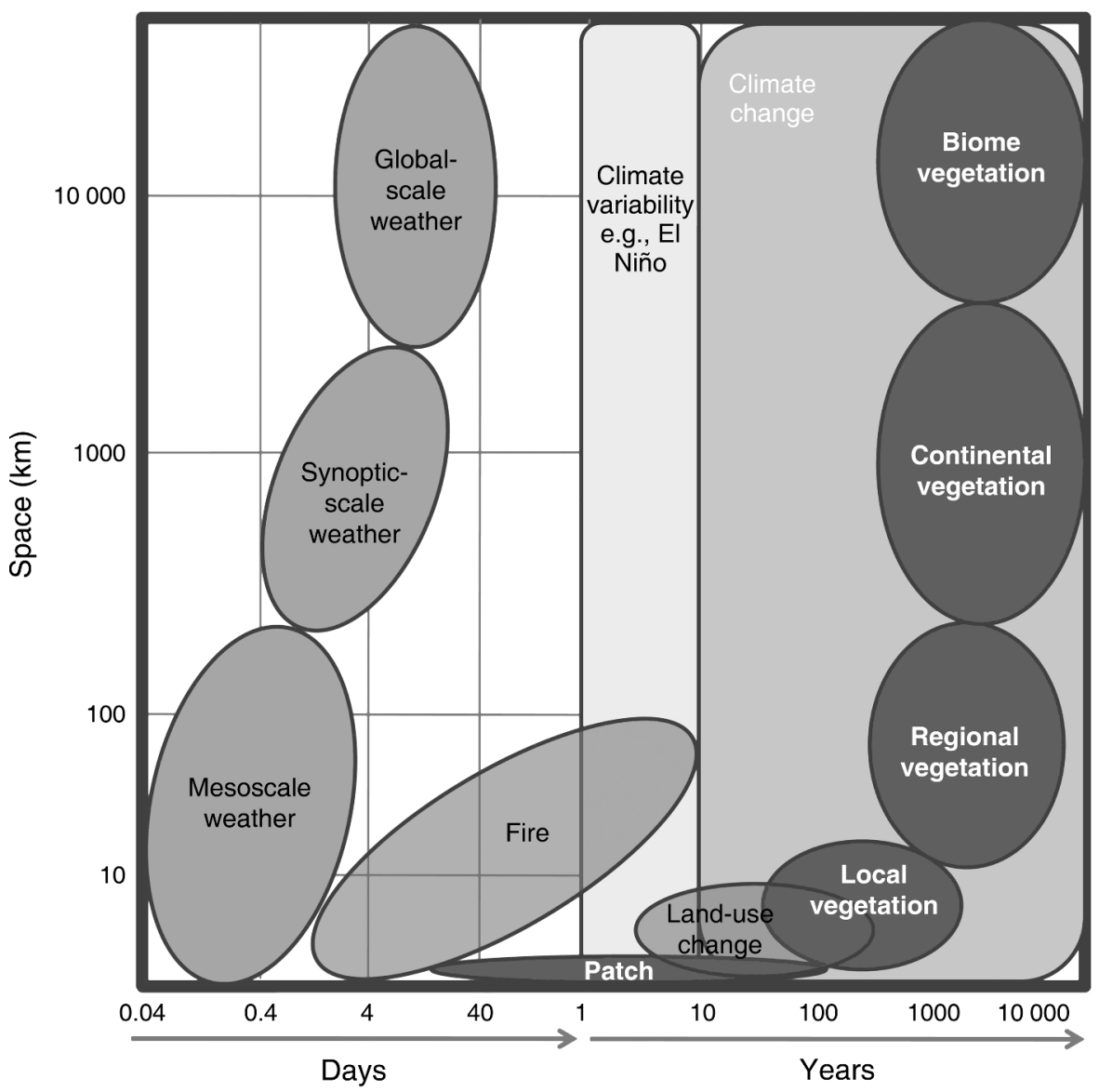

FIG. 1. Space and time scales of key ecosystem-driving processes (weather, climate variability and climate change, fire, and land-use change) and concomitant vegetation distributions. This diagram is modified from Dickinson (1986: Fig. 9.9).

of changes in thermal regimes associated with the Pleistocene glacial cycles and consideration of related issues such as the scale of refugia (micro or macro), the difference between refugia for temperate vs. coldadapted species, barriers and bridges to species migration from rising/falling sea levels, and the genetic consequences of population expansion and contraction (Watari et al. 2008, Stewart et al. 2010).

In considering the distinction between refuges and refugia it is helpful to consider the space-time scales of climatic and other processes that can threaten species habitat and their persistence (Fig. 1), which include: mesoscale weather events (hours to days) such as fronts, thunderstorms, tornadoes and squalls; synoptic-scale weather events (days to weeks) such as floods, heat waves, cold snaps, and cyclones; global-scale weather (days to months) and climate variability such as El Niño (years); fire (days to years), and land-use change (decades to centuries or longer). Climate change has impacts over the largest spatial and temporal scales. Commonly, it is assumed that the threatening process that has reduced the area of suitable habitat locations is temporary. In that case, at some point in the future favorable conditions return and the reduced habitat area functions as source habitat from which a species disperses. If the reduction in suitable habitat is not temporary, then the species undergoes permanent range restriction to what are effectively relict populations. Consistent with the distinction made by Keppel et al. (2011), the term habitat refuge is used here to refer to contractions in the range of suitable habitat over relatively shorter timescales (days, years, decades, centuries). It follows that refugia refers to species-range dynamics in response to global climate change reflecting longer timescales. We further suggest that given the relatively short timescales involved, habitat locations that might function as refuges in response to human forced, rapid climate change can be called "potential climate-change refuges."

There is renewed interest in the concept of refuges as the result of climate-change projections (IPCC 2007) and in identifying locations that might limit negative impacts, though the distinction made here between refuges and refugia is not necessarily made by others working on this problem, e.g., Barnosky 2008. While potential climate-change refuges are being primarily 
considered in terms of rising temperatures (Ashcroft 2010), change in the water balance is also ecologically significant due to, among other things, the dependence of photosynthesis on water availability (Beerling and Woodward 2001) and "bottom-up" trophic impacts of climate-driven changes in net ecosystem productivity (Brown et al. 2004). Among climate-change predictions is the likelihood that current regional trends may become more extenuated and intensified so that wet areas become wetter and drought conditions become pronounced (Bates et al. 2008).

Even in the absence of climate change, habitat refuges play an important role in the persistence of wildlife in bioregions subject to drought condition (Morton et al. 2011) and wildfire. For example, Northern Australia is subject to a monsoonal climate with a wet summer and long ( $\sim 7$-month) dry season (Linacre et al. 1977). Locations that remain moister during the dry season as the result of run-on water or groundwater discharge can function as seasonal habitat refuges where many species are able to persist and then disperse from to repopulate the surrounding landscape once the wet season returns (Woinarski et al. 1992) consistent with the habitat source-sink theory of Pulliam (1988). Much of the Australian continent is subject to high year-to-year variability in rainfall, with even the moister eastern ranges not immune to irregular drought conditions (Hobbs et al. 1998). These two drought regimes (regular seasonal and irregular year-to-year variance) are also found around the tropics and in other southernhemisphere continents (Hobbs et al. 1998). Similarly, much of the Australian continent is fire prone, the occurrence of large fires being statistically related to the seasonality and interannual variability in rainfall (Russell-Smith et al. 2007). Unburned areas (including mesic gullies) act as fire refuges. While historically the fire regime has been largely driven by rainfall, Pechony and Shindell (2010) have proposed that climate change will cause a shift to a temperature-driven fire regime.

Identifying current drought and wildfire refuges, and potential climate-change refuges, is not straightforward. Species vary in their habitat requirements and scale of movements (Mackey and Lindenmayer 2001) and various paleo-evidence points to the individualistic response of species to past climate change (Stewart et al. 2010). However, it is equally true that a given landscape ecosystem supports an ecological community and an array of species with the necessary life-history attributes to exploit the available habitat resources. Southwood $(1977,1988)$ argued that variability in the distribution and availability of habitat resources operates as a selective force on the evolution of animal lifehistory strategies and tactics. From this perspective, the vegetation cover can be considered as the habitat templet on which animal life-history strategies are forged (Townsend et al. 1997), defined by three axes: (1) habitat productivity as a measure of growth potential, (2) habitat resource stability, (3) adversity or stress. Mackey et al. (2008) suggested that these three axes can be represented by space/time variability in the greenness (fraction of photosynthetically active radiation intercepted by the sunlit canopy, fPAR (Sellers 1985) and by the primary productivity (gross primary productivity, GPP) of the vegetation. GPP and fPAR can be used to define the habitat templet because the biomass produced from photosynthate is the basis of terrestrial food webs, and the emergent vegetation structure provides essential shelter and nesting resources (Berry et al. 2007).

Vos et al. (2008) suggested use of the term "ecosystem hotspots" for locations where climate refugia for a significant set of species coincide. We propose the term ecosystem greenspots for locations that may function as drought and fire micro-refuges for multiple species, to highlight the relationship at such locations between water and PPAR and primary productivity. The term micro-refuge is used here sensu Bennett and Provan (2008) to help clarify that we are referring to habitat patches within a bioregion. Of particular interest for both conservation and climate-change adaptation planning are locations that currently function as microrefuges from drought and fire-threatening processes that may become more persistent in certain bioregions under future climatic conditions.

Here we present an approach to identifying and mapping ecosystem greenspots that may have functioned as habitat refuges during the decade commencing July 2000. While drawing upon the ecological theories of habitat productivity noted above, our approach is empirically based on a continental time series of remotely sensed land-cover data. We use as a case study for testing our methodology the Great Eastern Ranges of New South Wales, Australia. This region is a recognized connectivity conservation corridor, possesses a rich diversity of species and ecosystems, and encompasses significant climatic gradients (Mackey et al. 2010).

\section{Methods \\ Description of case-study region}

The Great Eastern Ranges (GER) refers to the 2800$\mathrm{km}$-long expanse of north-south interconnected natural land that lies principally along the Great Dividing Range and Great Escarpment of eastern Australia (Mackey et al. 2010; see Plate 1). We defined the casestudy region as the portion of the GER region within the state of New South Wales but extending into northern Victoria and southern Queensland states so that the boundary was delineated by natural bioregional boundaries (Thackway and Cresswell 1995) rather than administrative divisions. The total area of the casestudy region is $46.7 \times 10^{6}$ ha but analyses were restricted to the $23.9 \times 10^{6}$ ha within the study region that supports native vegetation cover (Fig. 2).

The case-study region encompasses subtropical, temperate, and alpine thermal regimes, a strong declining 

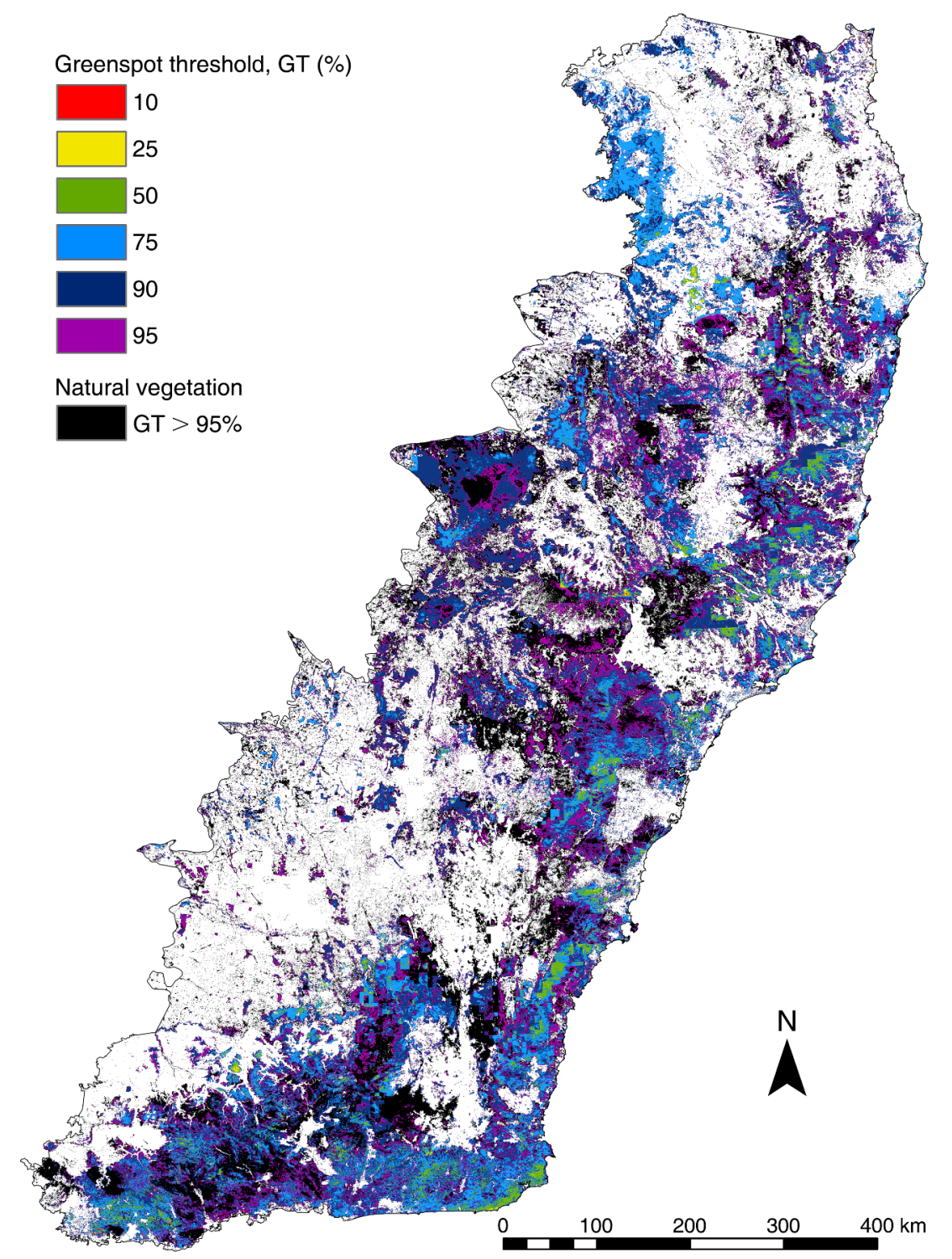

FIG. 2. Ecosystem greenspot index (percentiles) for the case-study region of 46.7 million hectares within the Great Eastern Ranges mainly in New South Wales, Australia, but extending into northern Victoria and southern Queensland states to conform to natural bioregional boundaries. Analysis is restricted to $23.9 \times 10^{6}$ ha within the study area comprising those areas with native vegetation cover. The greenspot index is derived from fPAR time-series data (fPAR is the fraction of photosynthetically active radiation intercepted by the sunlit canopy).

east-west precipitation regime, and complex topography and landform that includes a north-south aligned coastal escarpment and the major continental watershed divide between coastal and inland-flowing river systems. A wide range of ecosystem types are represented within the boundaries of the study area, including coastal forests and heathland, temperate and subtropical rainforests, alpine herbfields, and semiarid woodlands. These ecosystems are associated with climatic, topographic and edaphic environmental gradients (Appendix A).

Temporally, the study was restricted to the 10-year period from 1 July 2000 to 30 June 2010. During five of these years the annual precipitation over southeastern Australia was $<90 \%$ of the long-term (1900 to 2010) average of $627 \mathrm{~mm} / \mathrm{yr}$. The most extreme drought conditions in southeastern Australia occurred during 2006 with average precipitation of $380 \mathrm{~mm}$ (Bureau of Meteorology 2011) (Appendix B).

\section{Data analysis}

Spatial analyses were undertaken using the ArcMAP 9.3 (ESRI 2009) and IDRISI Taiga geographic information systems (Clark Labs 2008). The spatial unit of analysis was a regular matrix of grid cells at a 9" resolution $(\sim 250 \mathrm{~m})$. 


\section{Defining ecosystem greenspots for the case-study region}

For the case-study region we derfived a 10 -year monthly time series (July 2000-June 2010) of fPAR, the fraction of photosynthetically active radiation intercepted by the sunlit vegetation canopy. The source data for the fPAR calculations were continental time series of normalized-difference vegetation index (NDVI) values from the NASA MODIS 16day L3 Global $250 \mathrm{~m}$ (MOD13Q1) satellite imagery (Paget and King 2008). The first steps in the calculation involved the identification of grid cells that were affected by cloud contamination or sensor errors. These were detected through analysis of the time series of NDVI 16-day composite gridded data. Where the value of a grid cell was $<90 \%$ of the value of the corresponding grid cell in the preceding and subsequent images of the time series it was assumed to be erroneous. A corrected value was calculated as the average of the values of the preceding and subsequent images. Following this correction of "dropouts" through the NDVI time series, "spikes" were identified by a similar approach but where the value of a grid cell exceeded $110 \%$ of the value of the corresponding grid cell in the preceding and subsequent images. Averages of values of the corresponding grid cells in the preceding and subsequent images of dropout-corrected time series were substituted for the spike-affected grid cells. Following the corrections for dropouts and spikes we generated a monthly time series of mean daily NDVI for the period from 1 July 2000 to 30 June 2010. We assumed that the NDVI values of the 230 grids of corrected data represented grid-cell mean NDVI over the 16-day period and weighted the contributions to the monthly mean NDVI accordingly. We calculated the mean monthly fPAR for all months ( $t=1$ to 120$)$ in the time series using the following equations:

$$
\operatorname{fPAR}(t)=1.118 \mathrm{NDVI}(t)-0.168
$$

where $\operatorname{NDVI}(t) \geq 0.15$, and

$$
\operatorname{fPAR}(t)=0
$$

where $\operatorname{NDVI}(t)<0.15$. We assumed that with NDVI $<0.15$ the surface cover is devoid of green foliage.

The time series was analyzed to encapsulate the full growing season, thus a year was measured from the beginning of July to the end of June.

The fPAR data set was used to identify grid cells that over the time series had the highest fPAR values with the least temporal variation.

For this analysis, we stratified the case-study region by major vegetation type so that refuges were identified relative to ecosystem type. A map of the native vegetation cover for the study region was produced by combining spatial data sourced from government agencies. For the state of Victoria, the data source was Department of
Sustainability and Environment (2004) and for Queensland, the Queensland Herbarium (2009). New South Wales was divided into eastern and western sections defined by the Interim Biogeographic Regionalisation for Australia (IBRA; Thackway and Cresswell 1995). The vegetation data for the eastern section was taken from Keith (2004) and for the western portion we used data sourced from ESCAVI (2003). These vegetation data were combined to create a digital map showing the geographic distribution of the 13 major vegetation ecosystem types (Appendix A). The vegetation ecosystem types were defined in terms of the dominant vegetation structure (height and cover) and floristics, and are representative of the major patterns of native vegetation as they reflect the dominant physical environmental controls.

The ecosystem greenspots mapping was based on an index calculated from the fPAR data set. The index required four parameters: (1) the mean fPAR for the 120 months of the time series and (2) the coefficient of variation. These provide information on the long-term average canopy fPAR and its variability. (3) The coefficient of variation of the 12 long-term mean monthly (July-June) fPAR values. This provides information on the average within-year variability in fPAR. This coefficient of variation is expected to be low in systems dominated by evergreen canopy cover, for example, eucalypt forests. In contrast the coefficient is expected to be largest for grid cells that have cover comprised solely of seasonally green vegetation. (4) The minimum annual mean fPAR for the 10 years of the time series provides information on the extreme of between-year variability for each grid cell. The procedure for calculating these parameters and the index are detailed below. Analyses were performed on a grid-cell basis. Here, $F$ refers to fPAR.

Step 1. Calculate the long-term mean fPAR and its coefficient of variation for the 10-year time series.

The mean $F$ of the 10-year time series $\left(\bar{F}_{t}\right)$ was calculated for each grid cell:

$$
\bar{F}_{t}=\sum_{y=1}^{10} \sum_{m=1}^{12} F_{m, y} / t
$$

where $m$ is month ( 1 to 12 corresponding to July, August, September...May, June), $y$ is the year of time series ( 1 to 10 , commencing 1 July 2000), and $t$ is the total number of months (120) in the time series.

The corresponding coefficient of variation $\left(V_{t}\right)$ captures variability across the time series:

$$
V_{t}=\frac{\sigma(t)}{\mu(t)} .
$$

Step 2. Calculate the long-term monthly mean fPAR and its coefficient of variation.

The 10 -year mean $F$ value for each month $\left(\overline{F_{m}}\right)$ was calculated for each grid cell: 


$$
\overline{F_{m}}=\sum_{y=1}^{10} F_{m, y} / 10 .
$$

We used the $12 \overline{F_{m}}$ values to calculate the coefficient of variation $\left(V_{m}\right)$ thereby capturing the long-term withinyear (monthly) variation:

$$
V_{m}=\frac{\sigma(S)}{\mu(S)} \quad S=\left\{\overline{F_{m}} \mid m=1 \ldots 12\right\}
$$

where $\sigma(S)$ is the standard deviation of $S$ and $\mu(S)$ is the mean of $S$.

\section{Step 3. Calculate the mean $P P A R$ and the minimum $f P A R$} within each year of the time series.

For each year $(y)$ of the 10 -year time series, the mean $F\left(\overline{F_{y}}\right)$ was calculated for each grid cell:

$$
\overline{F_{y}}=\sum_{m=1}^{12} F_{m, y} / 12 .
$$

We then found the minimum $\overline{F_{y}}$ value within the 10 -year time series $\left(\min \overline{F_{y}}\right)$.

Step 4. Mapping the geographic location of greenspot refuges.

The case-study region was stratified by the 13 vegetation types, and for each vegetation type the cumulative cell frequencies of $\bar{F}_{t}$ and $V_{m}$ within vegetation types were calculated. For each vegetation type values of $\bar{F}_{t}^{p}$ and $V_{m}^{p}$ corresponding to the 10th, 25th, 50th, 75th, $90^{\text {th }}$, and 95 th percentiles $(p)$ were identified.

Grid cells within vegetation types were flagged as being greenspot refuges if (1) $\min \bar{F} y \geq \bar{F}_{t}^{p}$ and (2) $V_{t} \leq$ $V_{m}^{p}$. This evaluation was repeated for the 10 th, 25th, 50th, 75th, 90th, and 95th percentiles.

\section{Fire mapping}

As fire kills living foliage (depending on fire type and intensity), fire events should result in a subsequent drop in the fPAR of native vegetation. Image ratio analysis (IDRISI Taiga_image ratio function, earliest/latest) was used to examine change in fPAR over two-month periods between October and April for each year. The maximum value of the image ratios was found for each grid cell for each time-period. Finally, a maximum value was identified for each grid cell for the decade. Grid cells having native vegetation cover were identified as being fire affected where the maximum value of the image ratios over the decade was $\geq 3.0$.

\section{Diagnostic analyses}

GIS coverages of topographic position, slope, aspect, and distance from major streams at a spatial resolution commensurate with the fPAR data were obtained from the study of Mackey et al. (2008). These environmental layers were used to undertake diagnostic analyses with the aim of revealing potential causal processes underlying the mapped ecosystem greenspots.

\section{Conservation significance}

It was beyond the scope of this study to investigate which species or functional groups potentially utilize the mapped ecosystem greenspots. However, we did examine the distribution of greenspots in relation to patterns of spatial turnover in the species composition of vascular-plant communities throughout the case-study region, previously modeled by Ferrier et al. (2010), using the generalized dissimilarity modeling (GDM) approach of Ferrier et al. (2007). This earlier study employed data on the occurrence (presence or absence) of 4268 species of vascular-plant species at 9340 survey plots across the case-study region to fit a model predicting the compositional dissimilarity (Sørenson index) between any pair of locations within the region as a nonlinear multivariate function of 23 climate, terrain, and soil attributes mapped at $250-\mathrm{m}$ grid resolution.

The geographic distribution of the vascular-plant survey plots are shown in Appendix $\mathrm{C}$ while Appendix $\mathrm{D}$ is a histogram of the plots in relation to their estimated greenspot index values. A total of 5099 survey plots fell within native vegetation cover. The actual number of cells from which they are sampled is given in Appendix E which shows a reasonably consistent sampling proportionally across the greenspot percentile thresholds.

To visually assess the extent to which the mapped greenspot refuges are representative of variation in vascular-plant composition throughout the case-study region we first applied principal-components analysis (PCA) to the GDM-transformed values for all 23 environmental attributes at every 250 -m grid cell within the region. The density of all grid cells, and of those cells mapped as greenspots, were then plotted against the first three components (axes) of this PCA.

We also intersected the mapped ecosystem greenspots with the formal protected-area network for the casestudy region to identify the highest ranked greenspot locations as an indicator of their conservation management status (Department of the Environment 2008).

\section{RESULTS}

Fig. 2 shows the distribution of grid cells falling within the ecosystem greenspot thresholds (percentiles) for the case-study region. The large geographic extent of the study region, together with the relatively fine gridcell resolution $(\sim 250 \mathrm{~m})$ results in the spatial distribution of the ecosystem greenspots $(\leq 25 \%)$ being visually obscured by the scale of mapping. A version of this map in KMZ format viewable in Google Earth is provided in the Supplement. The total area of ecosystem greenspots within the $25 \%$ threshold was 48406 ha, $\sim 0.2 \%$ of the total area of native vegetation in the study region.

The change in fPAR (the photosynthetically active radiation intercepted by the sunlit vegetation canopy) over the study period for a selection of grid cells representing a range of greenspot thresholds within the dry sclerophyll coast/montane ecosystem type is shown 


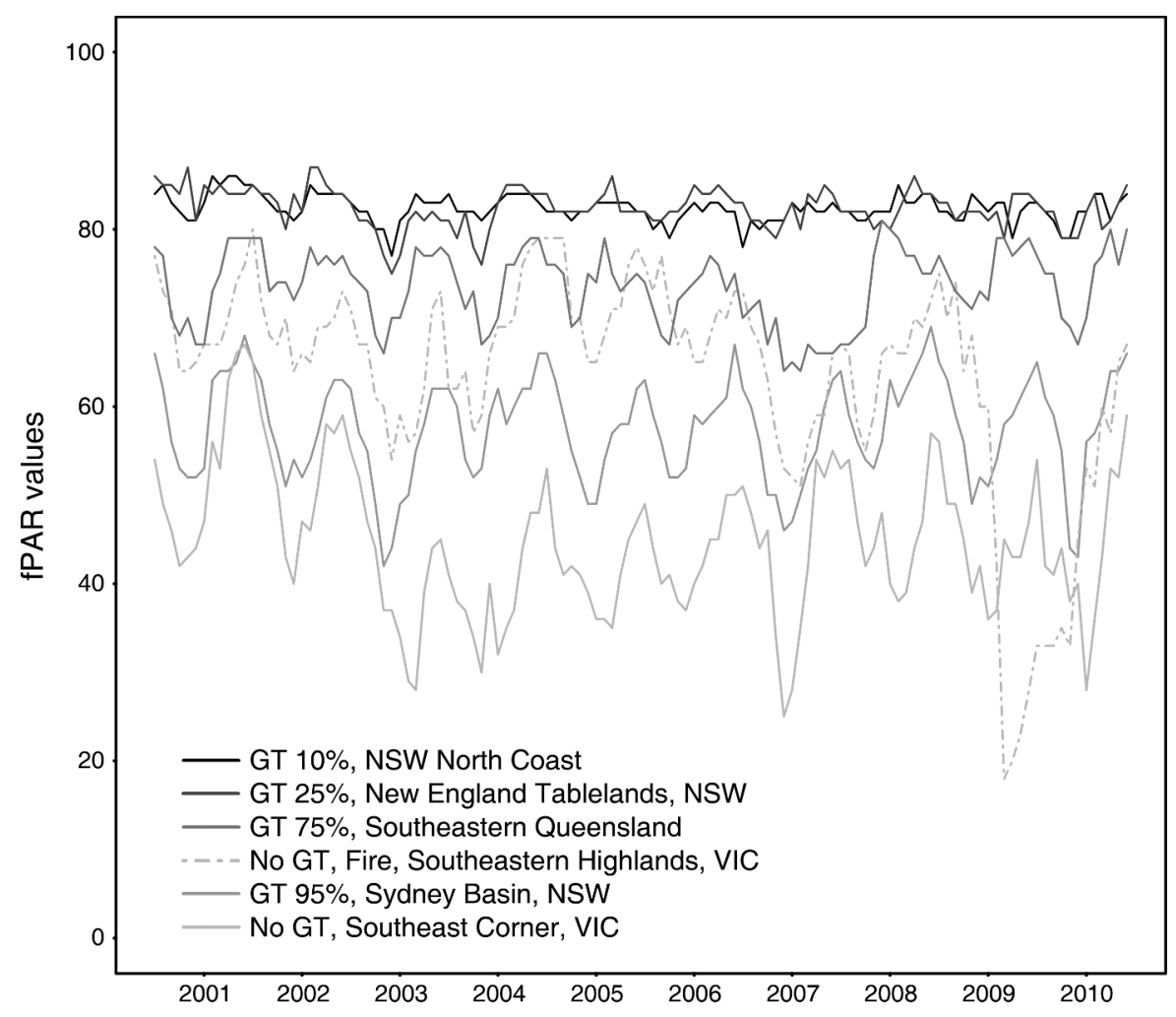

FIG. 3. Time series of monthly fPAR for selected grid cells within "Dry Sclerophyll Coastal/Montane" ecosystem type, representing greenspot thresholds (GT) of $10 \%, 25 \%, 75 \%, 95 \%$, and $>95 \%$ (labeled as "No GT").

in Fig. 3. The geographic locations of the selected cells are detailed in Appendix F. This ecosystem type is structurally an open forest (canopy height $\geq 30 \mathrm{~m}$, canopy cover $30-70 \%$ ) with a canopy dominated by native Eucalyptus species. The $10 \%$ and $25 \%$ greenspot thresholds have higher and less variable fPAR, illustrating the empirical basis to our ecosystem greenspot index. Temporal responses at selected grid cells for another five of the vegetation ecosystems in the case-study region are given in Appendix G.

By definition, ecosystem greenspots are sites that were not subject to wildfire during the study period (10 years). Fire-affected areas in the case-study region revealed by the image ratio analyses of the fPAR time series are shown in Fig. 4. A KMZ version is given in the Supplement. The total fire-affected area was $3.4 \times 10^{6}$ ha.

The results of the diagnostic analyses undertaken to explore the possible influence of aspect, slope, and topographic position on the occurrence of ecosystem greenspots are given in Appendix $\mathrm{H}$ as a set of frequency histograms.

The distribution (spread) of mapped greenspots (within the upper 25th percentile) relative to variation in vascular-plant species composition throughout the case-study region is depicted in Fig. 5. The scatter plots of pairwise combinations of the first three PCA axes of compositional variation were derived from the fitted generalized dissimilarity model. The spatial variation in species composition is shown in Appendix I for the both the entire case-study region and within native vegetation.

The conservation status of the mapped ecosystem greenspots, assessed in terms of the percentage of each vegetation ecosystem type found with the formal protected area network, is detailed in Table 1.

\section{Discussion}

The ecosystem greenspot index was used to map locations that may have functioned as micro-refuges from drought and fire during the decade commencing July 2000. We mapped the entire range of ecosystem greenspot index values but focused our diagnostic analyses and interpretation on cells within the top 25th percentile on the assumption that these locations will most likely function as micro-refuges during times of greatest climatic drought stress. This was a practical solution to our inability within the scope of the paper and available data to objectively delineate a threshold in our fPAR-based index that unequivocally delineates "refuge" from "non-refuge" for specific taxa. Note that conceptually the inverse of our greenspot index could be used to identify potential micro-refuges for species that have adaptive advantage at the drier and more variable part of the habitat templet and for which prolonged 


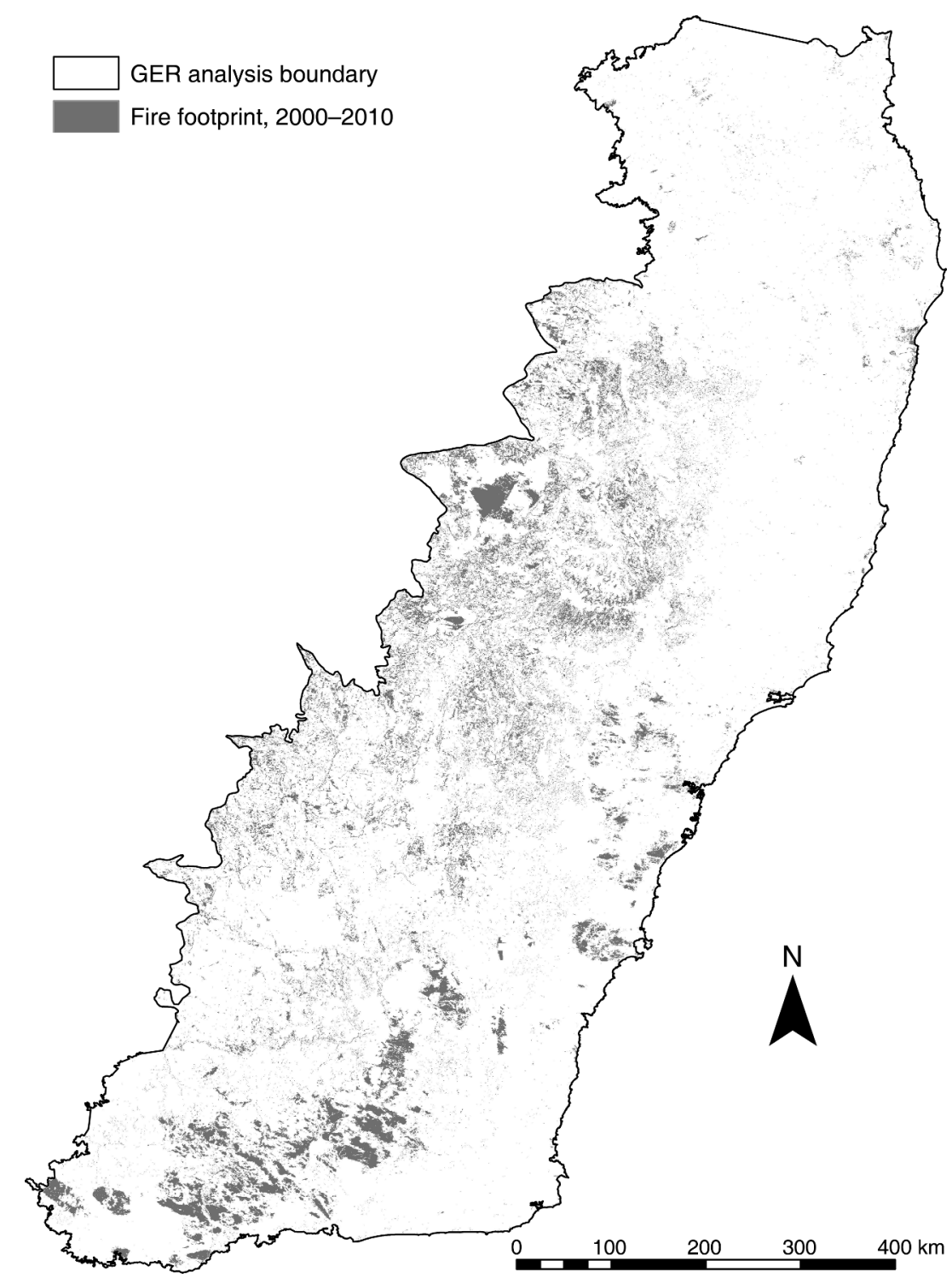

FIG. 4. Fire-affected native vegetation within the case-study region revealed by image ratio analysis of the fPAR time series for the period 2000-2010. GER is the Great Eastern Ranges, lying between the Great Dividing Range and Great Escarpment of Eastern Australia.

extreme wet climatic conditions (including fewer, less intense fires) present a threatening process.

Our estimate of fire affected areas $\left(3.4 \times 10^{6}\right.$ ha) is consistent with other sources of information for the case-study region. It was reported that between July 2001 to June 2006 fires burned $4 \times 10^{6}$ ha of New South Wales (multiple use and nature conservation reserve land) and Victoria (public land) (Montreal Process Information Group for Australia 2008). This included $3.3 \times 10^{6}$ ha of unplanned fires (i.e., wildfires) and 0.3 million hectares of planned (or prescribed) fires. In 2006-2007 the Great Divide Fires event was reported to have burned $\sim 1.05 \times 10^{6}$ ha of public and private land in southeastern Victoria, and in February 2009 fires burned a further $0.41 \times 10^{6}$ ha in southern Victoria (Romsey Australia 2010).

The results of the environmental diagnostic analysis suggest deterministic controls on the geographical distribution of potential micro-refuges. The aspect, topographic and drainage analyses are consistent with refuge areas being in more sheltered, "run-on" locations. Topographic sheltering, due to some combination of slope, aspect, and horizon shading, results in moister conditions due to reduced potential evaporation as the result of lower levels of direct radiation, all other factors being equal. Run-on locations are sites of more concentrated or reliable surface or subsurface water flow. Many land-based vegetation communities depend 

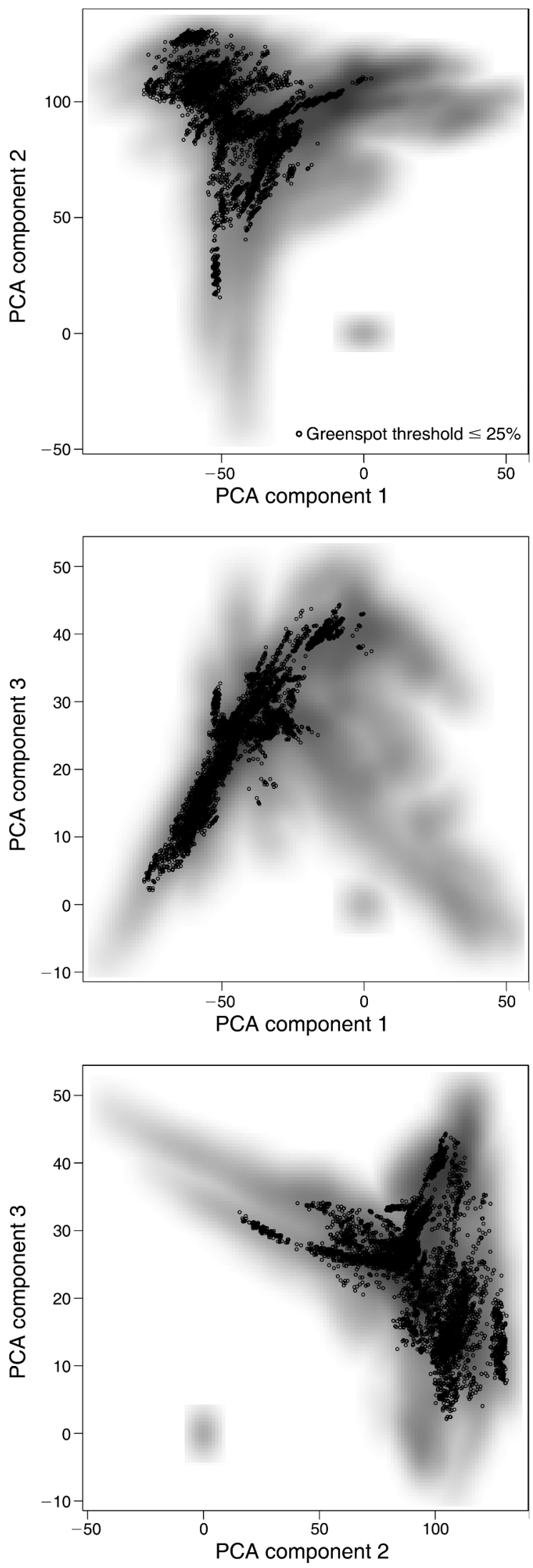

on groundwater which in turn supports animal communities. Deeply rooted perennial trees and shrubs, particularly in Australia, can access water in the vadose zone that has moved upward from the ground water through the hydraulic lift created by capillary action (Nevill et al. 2010). Plants at these locations can continue to access the water needed for photosynthesis when the surrounding landscape is subject to climatic drought. These wetter areas are also more likely to experience fewer, less intense fires, all other factors being equal. Mackey et al. (2002) found similar environmental controls on the distribution of fire refuges in the Central Highland mountain ash forests, and a review of microrefugia by Dobrowski (2011) also pointed to the importance of terrain in modifying mesoclimatic conditions. Our results are also consistent with those of Soderquist and Mac Nally (2000) and Mac Nally et al. (2000) who found that mesic gullies can function as drought micro-refuges for mammal and bird populations in sclerophyll forest ecosystems of south Australia.

However, the potential micro-refuges were also found to occur across topographic gradients, and trends are confounded by fire impacts, which have a stochastic component reflecting the spatial and temporal occurrence of ignition events, prevailing local weather conditions especially wind, and fuel loads. If the geographic distribution of potential drought microrefuges is influenced more by deterministic factors that influence plant water availability than they are by stochastic factors, then they are more likely to continue to so function under future climate. This may be the case where the wetter (and thus more productive) conditions are due to topographic, substrate (e.g., deep, wellstructured soil profiles), or groundwater conditions (e.g., recipients of groundwater discharge) that are relatively stable and unlikely to change as a function of climate. Should global climate change result in the surrounding region experiencing increased aridity with respect to average condition or variance, then these sites will remain relatively wetter and continue to function as drought and fire micro-refuges to some extent.

There is some evidence emerging that human-forced climate change may result in parts of southeastern Australia experiencing increased variability and intensity of extreme events, including droughts, and an overall drying trend in some bioregions. The poleward expansion of the Hadley circulation, together with an intensification of the hydrological cycle, tends to produce lower relative humidity and precipitation in

FIG. 5. The distribution (spread) of mapped greenspots (within the upper 25th percentile) relative to variation in vascular-plant species composition throughout the case-study region. Scatterplots of the pairwise combinations of the first three PCA axes of compositional variation were derived from the fitted generalized dissimilarity model $(5 a-c)$. 


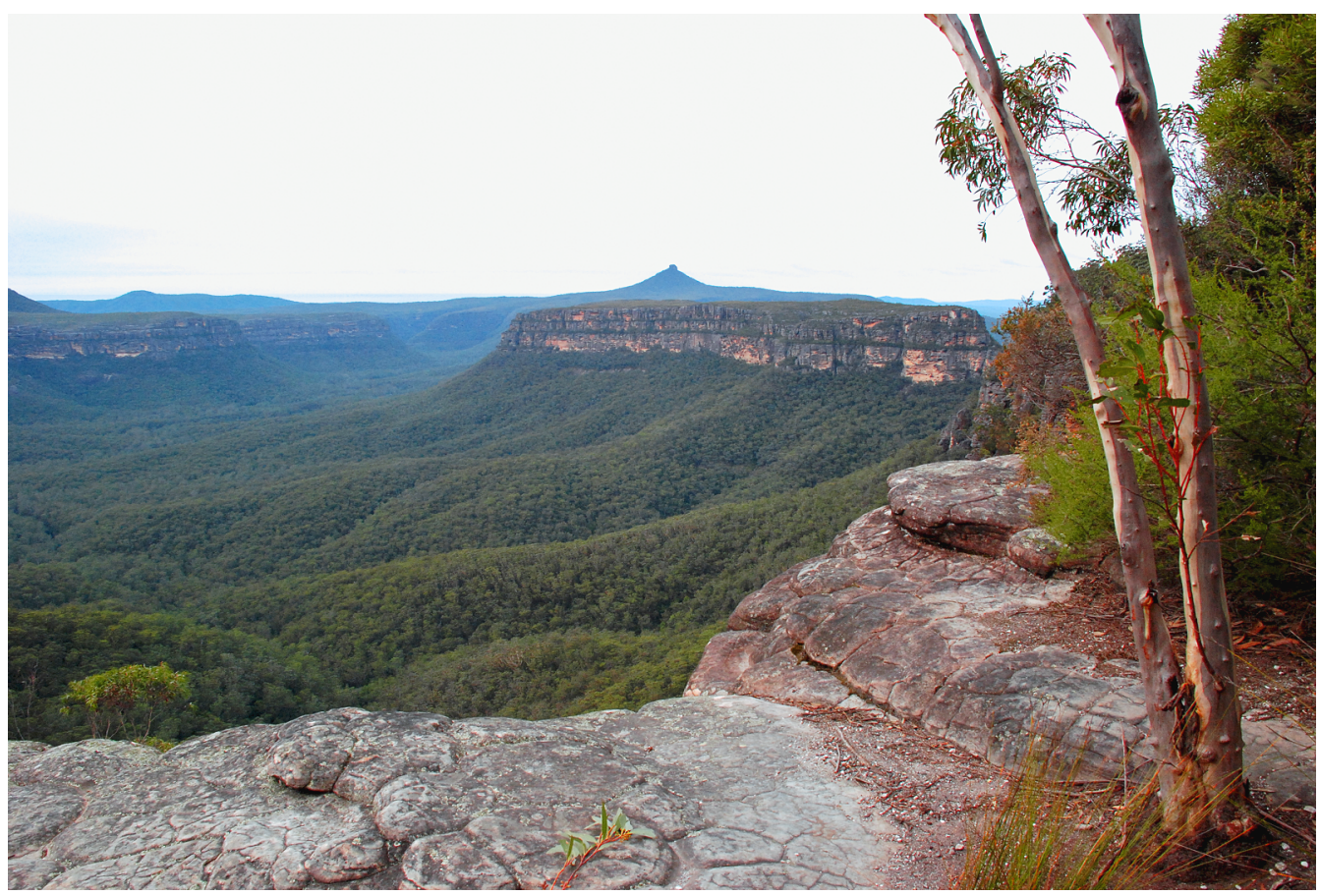

Plate 1. A vista of the Great Escarpment in the southeast of the study region. The Great Escarpment extends north-south along eastern Australia. In places, it is a dissected plateau edge, typically separating the tablelands from the coast. The pointed peak on the horizon is Pigeon House Mountain in Buddawang National Park. The geographic coordinates for Pigeon House Mountain are $35.34916^{\circ} \mathrm{W}$ latitude and $150.26511^{\circ} \mathrm{S}$ longitude. Photo credit: Ian Pulsford.

the subtropics (the desert regions), extending to the midlatitudes in some seasons. Simulations based on Intergovernmental Panel on Climate Change's A1F1 high-emission scenario for 2050 show a range of change in precipitation in southern Australia of $-7.5 \%$, with larger changes seasonally. Models show an increase in daily precipitation intensity but also in the number of dry days. Drought occurrence is also predicted to increase over most of Australia, with a substantial increase in fire weather risk likely at most sites in southeastern Australia (CSIRO 2007, Kirono et al. 2011).
The greenspots appear to be well spread across major gradients of variation in vascular-plant composition throughout the case-study region (Fig. 5), with some relatively minor exceptions (e.g., the higher end of PCA component 1 in Fig. 5a and b). These greenspots are therefore likely to include, or represent, a high proportion of all plant species occurring within the region. This finding has important implications for the value of greenspots as priority areas for focusing conservation attention. Investing in conservation management in these areas (e.g., weed control, exclusion of grazing by domestic stock) should help to ensure that a

TABLE 1. Conservation status of ecosystem greenspots defined in terms of percentage of greenspot area found within the formal protected-area network.

\begin{tabular}{|c|c|c|c|}
\hline Vegetation ecosystem type & $\begin{array}{l}\text { Greenspot refuge } \\
\text { threshold area (ha) }\end{array}$ & $\begin{array}{l}\text { Percentage of total } \\
\text { ecosystem area }\end{array}$ & $\begin{array}{l}\text { Percentage of greenspot } \\
\text { refuge in protected area }\end{array}$ \\
\hline Rainforests & 233 & 0.05 & 71 \\
\hline Wet sclerophyll & 813 & 0.02 & 34 \\
\hline Dry sclerophyll, west & 12880 & 0.29 & 22 \\
\hline Heathlands & 767 & 0.36 & 47 \\
\hline Alpine complex & 824 & 0.35 & 77 \\
\hline Grassy woodlands & 4084 & 0.10 & 32 \\
\hline Semiarid woodlands & 15238 & 1.64 & 22 \\
\hline Wetlands & 462 & 0.14 & 36 \\
\hline Grasslands & 172 & 5.86 & 77 \\
\hline Forested wetlands & 815 & 0.89 & 62 \\
\hline Mangroves & 86 & 1.07 & 68 \\
\hline Dry sclerophyll, coastal/montane & 12032 & 0.13 & 71 \\
\hline
\end{tabular}

Note: The threshold area is the area of a vegetation ecosystem type where the ecosystem greenspot index is $\leq 25 \%$. 
high proportion of the species in the case-study region are retained in locations that have the best chance of continuing to provide suitable habitat for them in the face of fluctuating or changing environmental conditions.

Assuming that the mapped micro-refuges play an ongoing role in supporting the persistence of many species (including mammals and birds) in the case-study region, information about their conservation status can be used in systematic conservation planning (Mackey et al. 2010). The extant native-vegetation cover in the study region is a legacy of $\sim 200$ years of land use since European settlement. Historically, protected areas have tended to be biased away from more productive landscape units, that is, land of higher value for human production systems which in the case-study region include agriculture, pastoralism, and forestry (Pringle 1995, Pressey et al. 2002). This bias is evident in the percentage of micro-refuge areas for each vegetation ecosystem type found within the formal protected-area network. The vegetation ecosystem types whose microrefuge areas are poorly represented in conservation reserves (wet sclerophyll forest, 34\%; dry sclerophyllwest forest, 22\%; grassy woodlands, 32\%; semi-arid woodlands, $22 \%$; wetlands, $36 \%$ ) have received more attention from agriculture, pastoralism, and forestry, leaving less area of land having higher and more reliable productivity available for conservation. The unprotected micro-refuges warrant consideration for special offreserve conservation management. The kinds of management activities will depend on, among other things, habitat condition and the threatening processes associated with the land uses. However, studies of relationships between micro-refuges, productivity, and birds elsewhere in Australia have pointed to the need to maintain these as habitat networks rather than to identify a prioritized subset of patches for conservation. This is because the particular patches used by species can vary from year to year and therefore it is the network of patches that enables the species to persist at the bioregional scale (Woinarski et al. 1992, Manning et al. 2007).

\section{Conclusion}

The approach developed here can be applied and is relevant to other regions of the world. Remotely sensed NDVI data are available globally (Bai et al. 2008) and can be used to construct fPAR time series. The role of micro-refuges in the persistence of species has been recognized across the world's arid zones, and in particular for the Australian, southern African, and South American continents (Morton et al. 2011). Furthermore, many regions of the world are subject to seasonally dry periods as a consequence of the location of the intertropical convergence zone, decadal oscillations in climatic wetness, and other processes that affect interannual variability in precipitation (Hobbs et al. 1998). While the particular species that may benefit from identification and mapping of micro-refuge networks will vary, the fundamental relations as explained by Pulliam's (1988) theory of source/sink habitat and Southwood's $(1977,1988)$ concept of the habitat templet, apply generically.

In considering the relationship among biodiversity, climate change, and ecosystem resilience and adaptive capacity, micro-refuge networks may be play an important role in maintaining beta-diversity at the bioregion scale. Doing so will also contribute to the stability, resilience and adaptive capacity of ecosystems (Thompson et al. 2009) in the face of ever-growing pressures from human-forced climate change, land use, and other threatening processes.

\section{ACKNOWLEDGMENTS}

We gratefully acknowledge the support of a grant from the CSIRO Climate Adaptation Flagship program. Thanks also to Scott Sanner for assistance with documenting the statistical equations.

\section{Literature Cited}

Ashcroft, M. B. 2010. Identifying refugia from climate change. Journal of Biogeography 37:1407-1413.

Bai, Z. G., D. L. Dent, L. Olsson, and M. E. Schaepman. 2008. Proxy global assessment of land degradation. Soil Use and Management 24:223-234.

Barnosky, A. 2008. Climatic change, refugia, and biodiversity: Where do we go from here? An editorial comment. Climatic Change 86:29-32.

Bates, B. C., Z. W. Kundkewicz, S. Wu, and V. P. Pallutikof, editors. 2008. Climate change and water. IPCC Technical Paper VI. IPCC Secretariat, Geneva, Switzerland.

Beerling, D. J., and F. I. Woodward. 2001. Vegetation and the terrestrial carbon cycle: modelling the first 400 million years. Cambridge University Press, Cambridge, UK.

Bennett, K. D., and J. Provan. 2008. What do we mean by "refugia"? Quaternary Science Reviews 27:2449-2455.

Berry, S., B. Mackey, and T. Brown. 2007. Potential applications of remotely sensed vegetation greenness to habitat analysis and the conservation of dispersive fauna. Pacific Conservation Biology 13:120-127.

Brown, J. H., J. F. Gillooly, A. P. Allen, V. M. Savage, and G. B. West. 2004. Toward a metabolic theory of ecology. Ecology 85:1771-1789.

Bureau of Meteorology. 2011. Australian climate variability and change time-series graphs. Commonwealth of Australia, Bureau of Meteorology, Canberra, ACT, Australia.

Clark Labs. 2008. IDRISI Taiga GIS. Clark University, Worcester, Massachusetts, USA.

CSIRO [Commonwealth Scientific and Industrial Research Organisation]. 2007. Climate change in Australia. Technical Report 2007. CSIRO, Canberra, ACT, Australia.

Department of Sustainability and Environment. 2004. EVC bioregional conservation status at 1:100,000. Department of Sustainability and Environment, editor. The State of Victoria, Melbourne, Victoria, Australia.

Department of the Environment, Water, Heritage and the Arts (DEWHA). 2008. The Collaborative Australian Protected Areas Database (CAPAD) 2008. DEWHA, editor. DEWHA, Canberra, ACT, Australia.

Dickinson, R. E. 1986. Impact of human activities on climatea framework. Pages 252-291 in W. C. Clark and R. E. Munn, editors. Sustainable development of the biosphere. Cambridge University Press, Cambridge, UK.

Dobrowski, S. Z. 2011. A climatic basis for microrefugia: the influence of terrain on climate. Global Change Biology 17:1022-1035. 
ESCAVI [Executive Steering Committee for Australian Vegetation Information]. 2003. Australian vegetation attribute manual: National Vegetation Information System (NVIS), version 6.0. Department of the Environment and Heritage, Canberra, ACT, Australia.

ESRI [Environmental Systems Research institute]. 2009. ArcMAP 9.3. ESRI, Redlands, California, USA.

Ferrier, S., G. Manion, J. Elith, and K. Richardson. 2007. Using generalized dissimilarity modelling to analyse and predict patterns of beta diversity in regional biodiversity assessment. Diversity and Distributions 13:252-264.

Ferrier, S., K. Williams, and T. Harwood. 2010. Spatial analysis of conservation priorities in the Great Eastern Ranges, Project 2: Compositional biodiversity. Report to the NSW Department of Environment, Climate Change and Water, CSIRO Climate Adaptation Flagship, Canberra, ACT, Australia.

Hobbs, J. E., J. A. Lindesay, and H. A. Bridgman, editors. 1998. Climates of the southern continents: present, past and future. John Wiley and Sons, Chichester, UK.

IPCC [Intergovernmental Panel on Climate Change]. 2007. Contribution of Working Group I to the Fourth Assessment Report of the Intergovernmental Panel on Climate Change: Summary for Policymakers. Approved at 10th Session of Working Group I of the IPCC, Paris, February 2007. http:// www.ipcc.ch/publications_and_data/ar4/syr/en/contents. html

Keith, D. 2004. NSW native vegetation map (Version 2.2a). Ocean shores to desert dunes: the native vegetation of New South Wales and the ACT. Department of Environment and Conservation, New South Wales, Australia.

Keppel, G., K. P. Van Niel, G. W. Wardell-Johnson, C. J. Yates, M. Byrne, L. Mucina, A. G. T. Schut, S. D. Hopper, and S. E. Franklin. 2011. Refugia: identifying and understanding safe havens for biodiversity under climate change. Global Ecology and Biogeography 21:393-404.

Kirono, D. G. C., D. M. Kent, K. J. Hennessy, and F. Mpelasoka. 2011. Characteristics of Australian droughts under enhanced greenhouse conditions: results from 14 global climate models. Journal of Arid Environments 75:566-575.

Linacre, E., J. Hobbs, and A. M. McGrath. 1977. The Australian climatic environment. John Wiley and Sons, Brisbane, Queensland, Australia.

Mackey, B., D. Lindenmayer, M. Gill, M. McCarthy, and J. Lindesay. 2002. Wildfire, fire and future climate: a forest ecosystem analysis. CSIRO Publishing, Melbourne, Victoria, Australia.

Mackey, B., J. Watson, and G. L. Worboys. 2010. Connectivity conservation and the Great Eastern Ranges corridor. An independent report to the Interstate Agency Working Group (Alps to Atherton Connectivity Conservation Working Group) convened under the Environment Heritage and Protection Council/Natural Resource Management Ministerial Council. Department of Environment, Climate Change and Water, Sidney, New South Wales, Australia.

Mackey, B. G., S. L. Berry, and T. Brown. 2008. Reconciling approaches to biogeographical regionalization: a systematic and generic framework examined with a case study of the Australian continent. Journal of Biogeography 35:213-229.

Mackey, B. G., and D. B. Lindenmayer. 2001. Towards a hierarchical framework for modelling the spatial distribution of animals. Journal of Biogeography 28:1147-1166.

Mac Nally, R., T. R. Soderquist, and C. Tzaros. 2000. The conservation value of mesic gullies in dry forest landscapes: avian assemblages in the box-ironbark ecosystem of southern Australia. Biological Conservation 93:293-302.

Manning, A. D., D. B. Lindenmayer, S. C. Barry, and H. A. Nix. 2007. Large-scale spatial and temporal dynamics of the vulnerable and highly mobile superb parrot. Journal of Biogeography 34:289-304.
Montreal Process Information Group for Australia. 2008. Australia's state of the forests report. Five-yearly report 2008. Bureau of Rural Sciences, Canberra, ACT, Australia.

Morton, S. R., J. Short, and R. D. Barker. 1995. Refugia for biological diversity in arid and semi-arid Australia. Biodiversity series, Paper number 4. Department of Environment, Sport and Territories, Canberra, ACT, Australia.

Morton, S. R., et al. 2011. A fresh framework for the ecology of arid Australia. Journal of Arid Environments 75:313-329.

Nevill, J. C., P. J. Hancock, B. R. Murray, W. F. Ponder, W. F. Humphreys, M. L. Phillips, and P. K. Groom. 2010. Groundwater-dependent ecosystems and the dangers of groundwater overdraft: a review and an Australian perspective. Pacific Conservation Biology 16:187-208.

Paget, M. J., and E. A. King. 2008. MODIS land data sets for the Australian region. CSIRO Marine and Atmospheric Research internal report number 004. CSIRO Marine and Atmospheric Research, Canberra, ACT, Australia.

Pechony, O., and D. T. Shindell. 2010. Driving forces of global wildfires over the past millennium and the forthcoming century. Proceedings of the National Academy of Sciences USA 107:19167-19170.

Pressey, R. L., G. L. Whish, T. W. Barrett, and M. E. Watts. 2002. Effectiveness of protected areas in north-eastern New South Wales: recent trends in six measures. Biological Conservation 106:57-69.

Pringle, H. J. R. 1995. Pastoralism, nature conservation and ecological sustainability in Western Australia's southern shrubland rangelands. International Journal of Sustainable Development and World Ecology 2:26-44.

Pulliam, H. R. 1988. Sources, sinks, and population regulation. American Naturalist 132:652-661.

Queensland Herbarium. 2009. Survey and mapping of 2006b vegetation communities and regional ecosystems of Queensland. Version 6.0b. R. M. Brisbane, editor. Department of Environment and Resource Management, Brisbane, Queensland, Australia.

Romsey Australia. 2010. Summary of major bush fires since 1851. Romsey, Victoria, Australia.

Russell-Smith, J., C. P. Yates, P. J. Whitehead, R. Smith, R. Craig, G. E. Allan, R. Thackway, I. Frakes, S. Cridland, M. C. P. Meyer, and A. M. Gill. 2007. Bushfires "down under": patterns and implications of contemporary Australian landscape burning. International Journal of Wildland Fire 16:361-377.

Sellers, P. J. 1985. Canopy reflectance, photosynthesis and transpiration. International Journal of Remote Sensing 6:1335-1372.

Soderquist, T. R., and R. Mac Nally. 2000. The conservation value of mesic gullies in dry forest landscapes: mammal populations in the box-ironbark ecosystem of southern Australia. Biological Conservation 93:281-291.

Southwood, T. R. E. 1977. Habitat, the templet for ecological strategies? Journal of Animal Ecology 46:337-365.

Southwood, T. R. E. 1988. Tactics, strategies and templets. Oikos 52:3-18.

Stewart, J. R., A. M. Lister, I. Barnes, and L. Dalén. 2010. Refugia revisited: individualistic responses of species in space and time. Proceedings of the Royal Society B 277:661-671.

Thackway, R., and I. D. Cresswell, editors. 1995. An interim biogeographic regionalisation for Australia (IBRA): a framework for establishing the national system of reserves. Version 4.0. R. Australia Nature Conservation Agency, Canberra, ACT, Australia.

Thompson, I., B. Mackey, S. McNulty, and A. Mosseler. 2009. Forest resilience, biodiversity, and climate change. A synthesis of the biodiversity/resilience/stability relationship in forest ecosystems. CBD Technical Series number 43. Secretariat of the Convention on Biological Diversity, Montreal, Quebec, Canada. 
Townsend, C., S. Doledec, and M. Scarsbrook. 1997. Species traits in relation to temporal and spatial heterogeneity in streams: a test of habitat templet theory. Freshwater Biology 37:367-387.

Vos, C. C., P. Berry, P. Opdam, H. Baveco, B. Nijhof, J. O'Hanley, C. Bell, and H. Kuipers. 2008. Adapting landscapes to climate change: examples of climate-proof ecosystem networks and priority adaptation zones. Journal of Applied Ecology 45:1722-1731.
Watari, Y., S. Takatsuki, and T. Miyashita. 2008. Effects of exotic mongoose (Herpestes javanicus) on the native fauna of Amami-Oshima Island, southern Japan, estimated by distribution patterns along the historical gradient of mongoose invasion. Biological Invasions 10:7-17.

Woinarski, J. C. Z., P. J. Whitehead, D. M. J. S. Bowman, and J. Russell-Smith. 1992. Conservation of mobile species in a variable environment: the problem of reserve design in the Northern Territory, Australia. Global Ecology and Biogeography Letters 2:1-10.

\section{Supplemental Material}

\section{Appendix A}

A figure showing the major vegetation ecosystem types in the study region (Ecological Archives A022-100-A1).

\section{Appendix B}

Two box-and-whisker-plot figures showing the range of temperature, precipitation, and elevation found in the case-study region (Ecological Archives A022-100-A2).

\section{Appendix C}

A figure showing the geographic distribution of the vascular plant survey plots (Ecological Archives A0022-100-A3).

\section{Appendix D}

A histogram of the plots in relation to their estimated greenspot index values. A total of 5099 survey plots fell within native vegetation cover (Ecological Archives A022-100-A4).

\section{Appendix E}

A table showing for each greenspot index percentile threshold, the number of grid cells from where the vascular plant survey plots are located, the number of plots, and the sampling proportion (Ecological Archives A022-100-A5).

\section{Appendix F}

A table listing the geographic coordinates of the selected cells used in Fig. 3 to show the greenspot index time series for the dry sclerophyll coast/montane ecosystem type (Ecological Archives A022-100-A6).

\section{Appendix G}

Five figures showing the fPAR ( ) time-series values for a set of grid cells for a selection of vegetation ecosystem types and greenspot thresholds. "No GT" indicates that the threshold exceeds 95\% (Ecological Archives A022-100-A7).

\section{Appendix $\mathbf{H}$}

Eight figures showing the distribution of ecosystem greenspot index values in relation to the aspect, slope, and topographic position of the corresponding grid cell (Ecological Archives A022-100-A8)

\section{Appendix I}

Two maps depicting the geographic variation in species composition as represented by the three-dimensional PCA analysis of the generalized dissimilarity modeling (GDM) of 4268 vascular plant species in the case-study region (Ecological Archives A022-100-A9).

\section{Supplement}

KMZ versions of the maps presented in Figs. 2 and 4, viewable in Google Earth (Ecological Archives A022-100-S1). 